\title{
Why-Rac? Revisiting the Traditional Paradigm for Writing About Legal Analysis
}

\author{
Laura P. Graham ${ }^{*}$
}

\section{INTRODUCTION}

You made the grades. You took the LSAT. You accepted an invitation to the law school of your choice. Now, you have to do it all over again. This time you need to make the law school grades, in order to be invited to join the law firm of your choice. To make the grade, you need to employ the IRAC (Issue, Rule, Application, Conclusion) method of case briefing for the next three years of your life. IRAC enables readers to easily follow your legal writing. ${ }^{1}$

IRAC . . f forms the fundamental building blocks of legal analysis. It is the process by which all lawyers think about any legal problem. The beauty of IRAC is that it allows you to reduce the complexities of the law to a simple equation. ${ }^{2}$

Sweeping statements like these, extolling the virtues of IRAC, ${ }^{3}$ are all too common on the Internet today. Novice law students may easily conclude that if they master IRAC, a successful legal career is all but assured.

Almost from legal writing's emergence as a discipline, ${ }^{4}$ the legal writing academy has recognized the limitations of IRAC, and criticisms of the paradigm have steadily mounted. ${ }^{5}$ Yet many legal writing

\footnotetext{
*2014 Professor of Legal Writing, Wake Forest University School of Law. B.A., 1986, Wake Forest University; J.D., 1994, Wake Forest University School of Law. I am grateful to Christine N. Coughlin \& Miriam E. Felsenburg for reviewing drafts of this Article and offering their insightful comments. I also wish to thank Sally Irvin for her valuable research assistance and the administration of Wake Forest University School of Law for its generous support.

1. August Jackson, How to Brief a Legal Case in IRAC Style, E-HOw, http://www.ehow.com/ how_6523636_brief-legal-case-irac-style.html (last visited Apr. 21, 2015).

2. The IRAC Formula, LAWNERDS.COM, http://www.lawnerds.com/guide/irac.html (last visited Apr. 21, 2015) (emphasis in original).

3. IRAC stands for Issue, Rule, Application, and Conclusion.

4. For a history of legal writing as a distinct discipline, see Mary S. Lawrence, The Legal Writing Institute the Beginning: Extraordinary Vision, Extraordinary Accomplishment, 11 LEGAL WRITING 213, 227 (2005). The first legal writing conference was held in 1984, and the Legal Writing Institute was formally established in 1986. Id.

5. For a detailed review of the criticisms of IRAC, see infra Parts II-IV.
} 
professors continue to cling to the IRAC paradigm, often treating it as the only path to legal writing success. ${ }^{6}$

In this Article, I urge the legal academy to revisit its reliance on IRAC as a tool for organizing and writing about legal analysis. I suggest instead a return to the roots of IRAC, using it only to illustrate the basic framework for conducting legal analysis, instead of presenting it as a template for writing that students should rigidly follow.

In Part II of the Article, I review the inherent deficiencies of IRAC as an organizational paradigm for legal writing, drawing on a wealth of literature from the legal writing community and other contingents of the legal academy going as far back as 1995. Then, in Part III, I discuss the more recently heard criticisms of IRAC from the rhetoric and storytelling perspective. In Part IV, I discuss practitioners' growing dissatisfaction with the rigid use of IRAC in legal documents. Finally, in Part V, I suggest a fresh view of IRAC that recognizes its value as a basic analytical framework but loosens its grip on our students as legal writers.

\section{INHERENT DEFICIENCIES OF IRAC}

The central inherent deficiency of IRAC - one that is almost universally recognized - is that it is too simplistic. "Formulas like IRAC and its progeny ... mask[] the series of complex, interrelated steps that students need to learn to analyze and write about legal problems in a sophisticated manner."7 In fact, in a 1995 issue of the Legal Writing Institute's Second Draft devoted to the pros and cons of IRAC, contributors addressed inadequacies in all four components of IRAC.

6. See, e.g., Terri LeClercq, The Success-And Failure-of IRAC, 50 TEX. B.J. 222, 222 (1987) (referring to IRAC as "the golden-rule acronym for organizing legal discussions"). Yet LeClercq acknowledged even then that "slavish adherence to IRAC creates reading problems for anyone other than a legal historian." Id.; see also Jeffrey Metzler, The Importance of IRAC and Legal Writing, 80 U. DET. MERCY L. REV. 501, 501 (2003) ("IRAC is the key to success on law school exams, the bar exam, and a successful career in litigation."); Gerald Lebovits, Cracking the Code to Writing Legal Arguments: From IRAC to CRARC to Combinations in Between, 82 N.Y. ST. B. Ass'N J. 64, 64 (2010) ("All legal writers will improve their writing skills and their submitted product by using IRAC or one of its many variations.").

7. Jane Kent Gionfriddo, Dangerous! Our Focus Should Be Analysis, Not Formulas Like IRAC, THE SECOND DRAFT (Legal Writing Inst., Tacoma, Wash.), Nov. 1995, at 2.

8. See generally The Value of IRAC, THE SECOND DRAFT (Legal Writing Inst., Tacoma, Wash.), Nov. 1995, at 1 . The editors of this issue noted at the outset the disagreement among legal writing professionals about IRAC:

Just about every comment sees some danger in using IRAC without flexibility. Beyond that the comments divide roughly into two categories: those that see any standard structural scheme as potentially truncating or skewing legal analysis and those that 


\section{A. Inadequacies of IRAC's Core Components}

\section{Issue (I) Component}

With regard to the issue component, one Second Draft contributor pointed out that often, before students can formulate the $I$ of an IRAC, they must do some preliminary analysis. ${ }^{9}$ This writer suggested:

Perhaps we should expand IRAC into something like '(QfrFR)+IRAC' in which $\mathrm{Q}=$ question, $\mathrm{fr}=$ the entire set of possibly relevant facts and rules, and FR = relevant fact(s) and rules used to formulate the I of the IRAC. We should emphasize that the terms within the parenthesis(QfrFR) - are the necessary preconditions for an IRAC analysis. ${ }^{10}$

The $I$ troubled another contributor for a different reason: "Assuming that I correctly understand ... the legal problem solving process, then analysis of a question raised by a legal problem should begin with the answer to that question. 'I' for issue, however, does not correctly convey that idea." 11

\section{Rule (R) Component}

The rule component of IRAC generated more commentary than the issue component. One Second Draft contributor wrote: "I find that the $\mathrm{R}$ or rule part of this formulation is often unclear to students ... . [M]any want to see 'rule' as a general premise only, forgetting that it must also include fact specific examples of how that general premise has been applied in the past." " 2 Her preferred acronym, IGPAC, compensates for this deficiency by "dividing the R into two pieces"- the general rule $(\mathrm{G})$

recognize the value of a standard structure, but may see a need to modify the elements of

IRAC to a greater or lesser extent.

Id. at 1 .

9. Dennis R. Honabach, "IRAC" or “(QfrFR) + IRAC," THE SECOND DRAFT (Legal Writing Inst., Tacoma, Wash.), Nov. 1995, at 8.

10. Id. Another contributor suggested (F)IRAC, a slightly simpler variation of Honabach's structure, with the $F$ representing the factual background (Honabach's "preconditions") that give rise to the narrow legal issue. Sally Ann Perring, In Defense of (F)IRAC, THE SECOND DRAFT (Legal Writing Inst., Tacoma, Wash.), Nov. 1995, at 12.

11. Kim Cauthorn, Keep on "TRRACING," THE SECOND DRAFT (Legal Writing Inst., Tacoma, Wash.), Nov. 1995, at 4. Cauthorn recommended replacing the $I$ with a $T$ (for Thesis), noting that TRRAC "sounds and looks more appealing" than IRAC, thereby "speed[ing] up [students'] understanding of it." $I d$. at 5.

12. Barbara Blumenfeld, Why IRAC Should Be IGPAC, THE SECOND Draft (Legal Writing Inst., Tacoma, Wash.), Nov. 1995, at 3. 
and precedent $(\mathrm{P})$ - thus allowing students to "more clearly grasp the necessary components of a rule section...."13 "With the IGPAC foundation reminding them that 'rule' includes precedent that decided specific fact situations, students see the 'rule' as more than an abstract principle. $" 14$

Another contributor recommended TRRAC as an alternative to IRAC. ${ }^{15}$ She too was troubled by the single $R$ in IRAC:

The law isn't always settled and even if it is, it isn't always immediately comprehensible. Consequently, it's usually not enough to simply identify the rule. In order for the reader to understand the writer's application of the rule (the " $\mathrm{A}$ " in the acronym), the reader also must understand the rule. Therefore, the reader needs an explanation of the legal rule. ... That's why I put two R's in my acronym. ${ }^{16}$

In a more theoretical criticism, one contributor noted that IRAC "encourages students to assume that there is a 'Rule' which is clearly called forth by the facts so that all they need to do is apply 'the rule' to get the right result. However, very often the choice among rules is the hardest question presented."17 Thus, to the extent that professors use IRAC rigidly in early legal writing classes, they may be tempted to avoid giving students assignments that require them to evaluate competing rules - a skill that all lawyers need. ${ }^{18}$

A later critic of IRAC, Michael Sinclair, went so far as to argue that while the $I, A$, and $C$ of IRAC are "pretty innocuous," the $R$ is "seriously misguided." $\mathrm{He}$ asked, "Are the proponents of IRAC serious about there being rules in cases? If so, what sort of rules could they be?" 20 Sinclair posited that the inclusion of the $R$ in IRAC rests on the assumption that "[j]udicial decisions (cases) stand for rules; there are rules in opinions, of much the same kind as we find in statute books. ${ }^{21}$ However, "[t]here are indefinitely many ways that a rule may be

13. Id.

14. Id. at 4. Blumenfeld acknowledged that like IRAC, IGPAC "has its limitations." Id. (noting that "[i]f, in an appropriate case, there is a good reason not to use IRAC/IGPAC, then [students] should not do so").

15. Cauthorn, supra note 11 , at 5 .

16. Id.

17. Marion W. Benfield, Jr., Thoughts on IRAC, THE SECOND DRAFT (Legal Writing Inst., Tacoma, Wash.), Nov. 1995, at 17.

18. This may be one reason that practicing lawyers are increasingly dissatisfied with the writing of new lawyers. For a fuller discussion of the practical deficiencies of IRAC, see infra Part IV.

19. Michael Sinclair, What is the " $R$ " in "IRAC," 19 N.Y.L. SCH. J. HuM. RTS. 87, 87 (2003).

20. Id.

21. Id. 
formulated to fit an opinion, and none is more authoritative than another." 22

Moreover, Sinclair noted, even assuming that the ordinary person has the skill to look up cases to find the "rules" they announce, "put [ordinary persons] on opposite sides of a dispute and they will come up with different rules from different cases, and different interpretations of the cases they find in common., ${ }^{, 2}$

Perhaps more problematic, Sinclair noted, is the fact that often, lawyers do not extract rules from single cases but from sets of cases. ${ }^{24}$ In fact, rule synthesis is generally among the earliest skills professors introduce to novice law students.

Typically, early in one's first year at law school, one is introduced to a set of cases - the opinions in appellate decisions, a new and formidable literary mode - and given a problem, that is, a set of facts and a client. My research and writing teacher in my first year of law school told us to "synthesize a rule" from the precedent cases. Such a "rule" is a verbal formula that accounts for all of the cases we'd been given. Then we were instructed to use that rule to tell the outcome of the case we had been given as a problem. This has proved successful as a method of introducing the mysteries and uncertainties of common law to nervous and bewildered One-Ls. ${ }^{25}$

Sinclair viewed the process of synthesis as rife with potential pitfalls: "There are indefinitely many such 'rules' that will fit all the cases in any given set of precedents and the present case (which we call 'reconciling') or that will fit all the precedents and not the present case (which we call 'distinguishing')." 26 Sinclair ultimately suggested that the $R$ of IRAC should instead be an $H$ for hypothesis, resulting in the acronym IHAC. ${ }^{27}$

\section{Application (A) Component}

With regard to the $A$ component, several contributors found fault with the mechanical use of IRAC, noting that the single $A$ in the acronym does not clarify that application often involves both analysis and counter-

22. Id. at 100

23. Id. at 97 .

24. Id. at 101 .

25. Id.

26. Id. at 102 (emphasis added).

27. Id. at 128 ("“[C]ommon lawyers worship at the shrine of the working hypothesis."” (quoting Lord Goff of Chieveley, The Future of the Common Law, 46 INT'L \& COMP. L.Q. 745, 752 (1997))). 
analysis and sometimes even policy analysis. ${ }^{28}$ "The skills of synthesizing legal authority, examining alternative lines of analysis, and assessing policy must be incorporated into any curriculum teaching legal analysis." 29 "To the extent an acronym is helpful," the writers suggested IRAAPC (Issue, Rule, Application, Alternative Analysis, Policy, Conclusion). ${ }^{30}$

The single $A$ representing Application may stem from the widelyaccepted view that IRAC originated as a representation of the deductive syllogism, with the $R$ (rule) representing the major premise and the $A$ (application) representing the minor premise. ${ }^{31}$ "The issue sets the operative terms of the premises, and the conclusion is compelled by the premises as a matter of logical necessity." "32

But in a true deductive syllogism, "each major premise must be a true statement of absolute certainty, and the minor premise also must be a true statement of absolute certainty, so that the conclusion is absolutely, unrefutably true." 33 Thus, only in the broadest, most theoretical sense does IRAC represent the true deductive syllogism.

In practice, even the simplest legal writing assignments (and exam questions, for that matter) rarely are designed to lead to absolutely, unrefutably true conclusions; in fact, many legal writing professors intentionally design problems that lend themselves to teaching counteranalysis $^{34}$ and that are therefore susceptible to more than one possible result. $^{35}$ Thus, the pure deductive syllogism breaks down almost immediately.

28. Ellen Lewis Rice et al., IRAC, The Law Student's Friend or Foe: An Informal Perspective, THE SECOND DRAFT (Legal Writing Inst., Tacoma, Wash.), Nov. 1995, at 13.

29. Id.

30. Id.

31. Joel R. Cornwell, Legal Writing As a Kind of Philosophy, 48 MERCER L. REV. 1091, 1113 (1997) ("Translated into Jerome Frank's model of how legal analysts view decisions, which is probably closer, graphically, to what most first-year law students envision, the correspondence would be thus: rule (major premise) $\mathrm{x}$ facts (minor premise) = result (conclusion).").

32. Id.

33. Michael D. Murray, Classical Rhetoric, Explanatory Synthesis, and the TREAT Paradigm 8 (Univ. of Ill. L. \& Econ., Working Paper No. 75, 2007), available at http://works.bepress.com/ michael_murray/9.

34. See laura P. Graham \& Miriam E. Felsenburg, The Pre-Writing Handbook for Law Students: A SteP-By-SteP Guide 111-13 (2013) [hereinafter PRe-Writing Handbook] (explaining to novice law students the role of counter-analysis in the pre-writing process).

35. "Virtually every objective memorandum problem in first-year legal writing courses is designed to present the student with some critically ambiguous fact or fact complex to be resolved in light of two lines of authority to which analogies must be drawn." Cornwell, supra note 31, at 1116. This, Cornwell says, is where the "duplicity of the IRAC algorithm" is revealed. Id. 
This highlights the inadequacy of the $A$ of IRAC: "The problem is all in the minor premise, for this is where ambiguity lies. How does one explain to a student how to fill in the crucial blank" in the application segment? ${ }^{36}$ As Joel Cornwell put it:

[t]he grafting of rules of law into various hypothetical fact patterns is a comparatively tame enterprise if both student and professor maintain the fiction that there is a correct application in any given instance and that this application is discoverable if enough variables are properly accounted in a rational calculus, the form of which, like the form of an applied mathematical calculation, is dictated as a matter of logical necessity. ${ }^{3}$

But legal decision-making is not strictly algorithmic; thus, the rigid use of IRAC "is undesirable, first, because it obscures the ethical significance of legal decision-making, and, second, because it obscures the rhetorical devices that are the very skills touted by the model's formalist adherents." 38

A better way to think of IRAC, according to Michael Murray, is as a model for the enthymeme. ${ }^{39}$

In an enthymeme, the major premise, whether it be explicitly stated or implied in the enthymeme, must be most probably true. In other words, truth with absolute certainty is not required, only probability of truth. Similarly, the minor premise must be most probably true, not absolutely, necessarily true. This produces a conclusion that also is most probably true; but this is acceptable because the enthymeme's purpose is to persuade, not to establish or define a proposition as a matter of scientific proof. ${ }^{40}$

Murray posited that the enthymeme is the better model for legal writing, "[g]iven the uncertainties of the law, where legal rules are constructed from multiple controlling authorities and, in certain instances, colored by persuasive authorities, and where facts might be uncertain or subject to multiple credible interpretations. ${ }^{, 41}$

36. Id. at 1114 .

37. Id. at 1111.

38. Id. at 1134.

39. Murray, supra note 33 , at 8 .

40. Id. at 8-9.

41. Id. at 9. According to Murray, Aristotle himself, the father of classical rhetoric, believed that the enthymeme "might be the only proper logical structure for a legal argument." Id. But see Soma R. Kedia, Redirecting the Scope of First-Year Writing Courses: Toward a New Paradigm of Teaching Legal Writing, 87 U. DET. MERCY L. REV. 147, 168-69 (2010) (noting that an enthymeme 
Whether a given analysis invokes the classical syllogism or the enthymeme, novice law students can find themselves at sea if IRAC is taught rigidly as an organizational tool. In her excellent book, Rhetoric for Legal Writers, ${ }^{42}$ Kristin Robbins-Tiscione pointed out that while legal syllogisms and enthymemes are deductive, the skills most often required to properly apply rules to facts are rule synthesis and reasoning by analogy - both types of inductive reasoning. ${ }^{43}$ Thus, in legal writing, IRAC is helpful only when students do not have to synthesize a rule or use analogical reasoning. ${ }^{44}$

Moreover, "the syllogism is not the only reasoning tool a lawyer can or should make use of." $" 45$

What is particularly unique about legal discourse... is that the reasoning used manipulates several types of data and knowledge, and does not simply employ a linear model of logical thought.... [T]he process of reasoning through a legal issue incorporates all these elements in distinctive ways.

First, in analyzing an issue that consists of some human need or problem, a legal writer must think about what types of legal and practical consequences or implications some facts might have. Then, the writer must use practical reasoning to make some suppositions about the outcomes of the case to advise her client regarding the client's options.

Perhaps one of the dissatisfactions with the $A$ of IRAC, then, is that it leads novice law students to reason - that is, to apply the law-in terms of absolutes (syllogistically), when the uncertainty of the law permits, or perhaps requires, at best reasoning in terms of probabilities (enthemematically). ${ }^{47}$ Just as a rigid approach to the $R$ may suggest to students that they must find the absolutely correct rule and must

"consists of a sequence of syllogisms, often with a premise assumed," which often "deceptively leads students to feel that 'logical' or deductive reasoning will form a complete legal analysis").

42. KRISTEN KONRAD ROBBINS-TISCIONE, RHETORIC FOR LEGAL WRITERS: THE THEORY AND PRACTICE OF ANALYSIS AND PERSUASION 118 (2009).

43. See id. at 111-13.

44. See id. at 118 (explaining that legal syllogisms are rarely indisputably true because two advocates representing opposing parties "are likely to articulate different, yet reasonable rules of law from the same statute, case, or line of cases;" in other words, there is rarely one true "rule").

45. Kedia, supra note 41, at 159-60 ("[L]egal reasoning has other features which do distinguish it from the type of classical logical principles a student might have employed in other scholarly discourse. In short, the syllogism is only subservient to a more expansive picture of legal reasoning.").

46. Id. at 161 .

47. Id. at 168-69. 
articulate it with absolute language, a rigid approach to the $A$ may suggest that "the rule" can be mechanically applied to the facts, point by point, when in fact, the process of legal analysis is far from mechanical and often requires intricate thinking.

I believe that IRAC works well for beginning legal writers only for the very simplest of assignments - the assignment that involves one simple, clearly articulated rule from one precedential case and a set of facts that either closely matches or dramatically differs from the precedential case. ${ }^{48}$ And this kind of assignment is rare after the first week or so of legal writing class; thus, if we teach IRAC at the outset, we must immediately begin to backtrack, modify, add caveats, et cetera.

\section{Conclusion (C) Component}

While the conclusion component of IRAC did not engender much discussion in the Second Draft issue, later critics of IRAC consider it perhaps the most problematic component. According to Kristen Robbins-Tiscione, when working with a syllogism (which IRAC is generally understood to represent), "[i]t is often easiest to begin with your conclusion and work backwards from there." ${ }^{, 49}$ Yet this is the very instinctual approach to legal analysis-jumping to a conclusion and then trying to make the analysis "fit" - of which we seek to break our novice law students. ${ }^{50}$

Donald Kochan has pointed out that a rigid approach to legal writing is counter to the attitude of "suspended conclusion." "When one adopts an attitude of suspended conclusion, one avoids being conclusory. One embraces doubt, accepts confusion and anxiety, examines alternative suggestions, overcomes impatience and habitual tendencies to rush

48. See Linda H. Edwards, IRAC Format Accomplishes the Limited Purpose it is Designed to Achieve, THE SECOND DRAFT (Legal Writing Inst., Tacoma, Wash.), Nov. 1995, at 7 ("The format is designed to help a novice writer organize the discussion of a single legal issue - that is, a single element or condition. That's all.").

49. ROBBINS-TISCIONE, supra note 42, at 151.

50. See Toni M. Fine, Comments on IRAC, THE SECOND DrAFT (Legal Writing Inst., Tacoma, Wash.), Nov. 1995, at 7-8 ("We all know that, if given the opportunity, students will react, rather than constructively create methods of analysis or challenge competing approaches.... [T] he very act of providing a formula reduces dramatically the likelihood that the students will ask themselves (and us) the hard questions about why things are done in a certain way; why a particular approach works best under a given set of facts and circumstances; what the theory is that underlies any systematic approach to legal analysis; etc.").

51. Donald J. Kochan, Thinking Like Thinkers: Is the Art and Discipline of an "Attitude of Suspended Conclusion”' Lost on Lawyers?, 35 SEATTLE U. L. REV. 1, 1 (2011). John Dewey coined the term "suspended conclusion" in his 1910 book, How We Think. Id. 
toward an answer, and otherwise avoids the impulsive tendencies toward a premature conclusion." 52 This attitude is critical for legal thinking, writing, and oral advocacy; indeed, it "replicates the ideal that is sought after in a neutral system of justice ...."53

Anecdotally, however, people have difficulty suspending conclusion for a number of reasons according to Kochan: (1) because "a state of perplexity is disagreeable to many;" (2) because some people tend to make snap judgments based on firm opinions that they are not mentally energetic enough to question; (3) because some people lack confidence in their own intelligence and fear making a final decision based on it; and (4) because today's prevalent "instant gratification" mindset makes it difficult to suspend conclusion. ${ }^{54}$

The IRAC framework makes it even more difficult for law students to suspend conclusion because it overemphasizes the relative importance of the $C$. Students think that, as one contributor to the 1995 Second Draft issue stated, "[i]f the Application section is well focused and complete, the Conclusion will follow inevitably." 55

If this were true, it would be a welcome relief to most law students, who "have been educated in environments where there is a right and wrong answer" and who "may tend automatically to return to the mindset that there must be a 'correct' response to the legal question presented." In fact, our students frequently complain about the ambiguity of how the law applies to our fact patterns. ${ }^{57}$ Students want to arrive at the answer,

52. Kochan, supra note 51, at 2.

53. Id. at 38 .

54. Id. at 46-49. This last reason is particularly compelling in light of the well-documented characteristics of the current generation of law students (the Millenials). See, e.g., Joan Catherine Bohl, Generations X and Y in Law School: Practical Strategies for Teaching the "MTV/Google" Generation, 54 LOY. L. REV. 775, 780 (2008) ("Since internet information appears on one's computer screen with little investment of time or effort, Gen X Y students have developed a predominantly passive relationship to information and an expectation of instant gratification."); see also Tracy L. McGaugh, Generation X in Law School: The Dying of the Light or the Dawn of a New Day?, 9 LEGAL Writing 119, 124 (2003) (noting that Generation X students "have come of age in an era when information and services can be accessed more and more quickly").

55. Diana Pratt, IRAC: A Useful Beginning, but Hardly a Panacea, THE SECOND Draft (Legal Writing Inst., Tacoma, Wash.), Nov. 1995, at 13.

56. Lisa T. McElroy \& Christine N. Coughlin, The Other Side of the Story: Using Graphic Organizers to Counter the Counter-Analysis Quandary, 39 U. BALT. L. ReV. 227, 233 (2010).

57. See, e.g., Miriam E. Felsenburg \& Laura P. Graham, Beginning Legal Writers in Their Own Words: Why the First Weeks of Legal Writing are So Tough and What We Can Do About It, 16 LEGAL WRITING 223, 255-56 (2010) (reporting survey results showing that many new law students felt frustrated because "the law was not as concrete as they thought"). One survey participant said, "I am learning that there are few hard and fast ways to apply the concepts we learn." Id. at 256. Another said, "[Studying the law] is researching in order to make an educated guess; the law is not as definite as I thought it would be." Id. 
in the syllogistic sense - the "absolutely, unrefutably true" conclusion. But this is simply not the nature of legal analysis; thus, our assignments usually involve scenarios that are susceptible to different avenues of analyses and different possible outcomes. A rigid reliance on IRAC places too much emphasis on the $C$, when the heavy lifting of legal analysis and writing is formulating the $R$ and thoroughly and (gasp!) creatively working through the $A .^{58}$

Another Second Draft contributor neatly captured the problem with the $C$ of IRAC: "When IRACian students make up their mind how the law applies to facts, they can undervalue opposing views. IRAC pushes students toward answers rather than arguments. IRAC is sleek and efficient; once 'Issue' emerges, 'Conclusion' ever beckons., 59 Thus, to combat this "IRACian" tendency, law students must be continually reminded that the outcome of a legal dispute is seldom clear and that they must consciously and habitually ponder the rival propositions.

\section{B. The Confusing Explosion of Variants on IRAC}

In sum, beginning at least as far back as 1995, scholars have identified deficiencies with the $I, R, A$, and $C$ of IRAC. The result is a growing list of alternative acronyms that, while designed to clarify the paradigm, may have only resulted in more confusion among law students.

In 2004, Terrill Pollman and Judith M. Stinson conducted a survey of legal writing professors to assess the varying terminology used in the classroom, and the survey responses revealed a basic uncertainty about

58. One scholar views this tension as both a strength and a weakness of IRAC:

IRAC conveys a truth that is powerful, profound, and utterly misleading (in the way powerful truths usually are). The powerful truth? That law is about rules. As anyone who teaches in the first year knows, that point can escape first year law students. Watching us [professors] twist and turn the rules to our own purposes, puzzling over the mix of history, economics, politics and philosophy that works its way into the notes, lectures and discussions, students can lose sight of the rules altogether. IRAC brings them back to earth. Unfortunately, the earth it brings them back to disappears under their feet. In the great first-year "gotcha," they learn that general rules don't decide particular cases. But IRAC neatly captures that, too. There's a gap between the $\mathrm{R}$ and the $\mathrm{C}$. The rule can't give you the conclusion; the A, the application, has to fill it in.

David J. Jung, I [Heart] IRAC, ThE SECOND DrAfT (Legal Writing Inst., Tacoma, Wash.), Nov. 1995 , at 10 .

59. Thomas H. Seymour, Between IRAC and a Hard Place, The SECOND Draft (Legal Writing Inst., Tacoma, Wash.), Nov. 1995, at 14. 
what to do with IRAC. ${ }^{60}$ Pollman and Stinson reported that $67 \%$ of the legal writing professors who responded to the survey used the acronym IRAC, "either alone or in conjunction with other organizational terms ...." How However, "[a]lthough participants are highly confident that they understand the IRAC acronym, they express low confidence in the IRAC variations . ...".62

In fact, Pollman and Stinson's research revealed that legal writing professors had become quite creative with the IRAC acronym; "[s]urvey participants listed the following acronyms in response to a variety of survey questions: FHRO; T/R/RE/RA/C; CRAC; IRLAFARC; RREACC; TRAC; FIRAC; TREAC; CRPA; IREAC; RREACC; IRAAAC; BaRAC; and C/RAC." ${ }^{33}$ However, the survey results suggested that "professors are not teaching students the broad vocabulary students need to talk about legal writing with those trained by other teachers." 64 This may have implications for students long after they leave law school, when they will be writing many different kinds of documents (not all of which may lend themselves to IRAC) and for many different readers (not all of whom may have been taught using IRAC). ${ }^{65}$

And today, ten years after Pollman and Stinson's survey, legal writing professionals continue to struggle to arrive at a more satisfactory acronym. In a 2012 article, Tracy Turner recognized that "[a]s legal writing scholarship proliferates alternative acronyms... lawyers may find themselves debating whether IRAC or CRuPAC or CREAC represents the ideal structure." believe that novice legal writers should be encouraged to develop their own organizational structures based on considerations such as audience, context, desired outcomes, strategy, story-telling, and problemsolving," ${ }^{67}$ while others "urge a balance between the use of paradigms and creative thinking." 68

60. Terrill Pollman \& Judith M. Stinson, IRLAFARC! Surveying the Language of Legal Writing, 56 ME. L. REV. 239, 241-42 (2004).

61. Id. at 261 .

62. Id.

63. Id. at 262 .

64. Id. at 242 .

65. For a discussion of practitioners' concerns about IRAC, see infra Part IV.

66. Tracy Turner, Finding Consensus in Legal Writing Discourse Regarding Organizational Structure: A Review and Analysis of the Use of IRAC and Its Progenies, 9 LEgAL COMM. \& RHETORIC: JALWD 351, 353 (2012).

67. Id. at 353-54 (citing many of the contributors in the 1995 publication on IRAC, THE SECOND DRAFT (Legal Writing Inst., Tacoma, Wash.), Nov. 1995, at 1).

68. Id. at 354 . 
Turner based her article on a review of the then-current editions of thirty legal writing textbooks published or republished between 2002 and $2012^{69}$ and forty-seven articles addressing IRAC and other acronyms. ${ }^{70}$ Her review confirmed that "IRAC has been heavily criticized as incapable of capturing the nuances of legal analysis." ${ }^{\text {"71 }}$ Turner recommended that instead of using IRAC rigidly, legal writing professors should focus on the four "core principles" of effective organization that legal writing texts and articles seemed to agree upon: (1) the need for rule-centered analysis; (2) the need for separating the analysis of discrete issues; (3) the need for synthesizing legal principles pulled from multiple sources; and (4) the need for a unified document, with roadmaps and transitions to tie the components of the analysis together. $^{72}$ When these four principles are emphasized in the legal writing classroom, students can effectively organize and communicate legal analysis without relying on a paradigm like IRAC or its variations. $^{73}$

\section{Rhetorical Deficiencies of IRAC}

More recently, IRAC has come under scrutiny from a relatively new contingency of the legal academy-the proponents of the "legal storytelling" approach to legal writing. ${ }^{74}$ Recognizing that legal reasoning and legal arguments often rest on probabilities and not certainties, ${ }^{75}$ these scholars and professors advocate a model of legal writing, especially persuasive legal writing, that emphasizes the

69. Id. Turner's review was subject to the availability of the texts in her law school library or on her bookshelves. Id. Twenty-five of the books addressed the use of acronyms as organizational paradigms. See id. at 354-55.

70. Id. at 355. Turner expounded on the meaning of some of the acronyms Pollman and Stinson had catalogued and added some new ones, including IREXAC (Issue, Rule, Explanation, Application, Conclusion) and RAFADC (Rule, Authorities, Facts (of the problem case), Analogizing and Distinguishing, Conclusion). Id. at 357-58.

71. Id. at 356 .

72. Id. at $355-63$.

73. Id. at 364 .

74. For a recent treatment of the legal storytelling movement, see Stephen Paskey, The Law is Made of Stories: Erasing the False Dichotomy Between Stories and Legal Rules, 11 LEGAL COMM. \& RHETORIC: JALWD 51, 54-59 (2014) (describing three storytelling movements, the third of which originated with legal writing faculty and focuses on "the use of stories in legal pedagogy and practice").

75. Murray, supra note 33 , at $17-18$. 
importance of the three pillars of classical rhetoric - logos, ethos, and pathos - in effective legal writing. ${ }^{76}$

More than fifteen years ago, Joel Cornwell observed that the nature of language "precludes any algorithmic formula for ethical decisionmaking." 77 Thus, "the IRAC model is undesirable, particularly if steps are not taken to demonstrate to the student that it is a model of conversational rhetoric as opposed to a model of logical calculus." ${ }^{, 78}$ Put another way, IRAC is a "clip-clop formula [that] allows students to traverse the legal landscape in a methodical manner" but that is "not structured to appeal to the reader's innate "understanding"' of the narrative of a situation. ${ }^{79}$

Consistent with these views, the legal storytelling movement has gained traction in recent years as an alternative way of thinking about legal writing. Proponents of legal storytelling echo Cornwell's criticism of IRAC: "The paradigm is, of course, a very useful tool for constructing a legal proof, and it is welcome relief for struggling first-year students because it feels like an 'answer' in a year of study that is otherwise nothing but questions." ${ }^{\text {" }}$ But they strongly assert IRAC's inadequacy: "The problem with IRAC ... is that it doesn't have much room for people." 81

Think about this. "I" refers to the legal issue under consideration. No people in there. The same goes for "R," the rule, which refers to the legal concepts and theories that will guide the court in reaching a decision. " $\mathrm{A}$ " has a bit of promise, if you take " $\mathrm{A}$ " to mean application, but even then, people are just objects upon which the rule operates. And if you take " $\mathrm{A}$ " to mean analysis, that is just more processing of the legal rule. The "C," or conclusion, is then just the legal conclusion that flows logically from the previous pieces.

Law, law, law. Where did all the people go in this process? ${ }^{82}$

76. See generally id. (discussing the audience's perception of the advocate's ethos); Kenneth D. Chestek, The Plot Thickens: The Appellate Brief as Story, 14 Legal Writing 127 (2008); Bret Rappaport, Tapping the Human Adaptive Origins of Storytelling by Requiring Legal Writing Students to Read a Novel in Order to Appreciate How Character, Setting, Plot, Theme, and Tone (CSPTT) Are as Important as IRAC, 25 T.M. COOLEY L. REV. 267 (2008).

77. See Cornwell, supra note 31, at 1092.

78. Id.

79. Rappaport, supra note 76, at 272.

80. See Chestek, supra note 76, at 129.

81. Id.

82. Id. at $129-30$. 
In the applied storytelling realm, IRAC is viewed simply as one possible method of constructing small pieces of the larger puzzle that is an appellate brief - as "merely one type of material that a writer can use to construct a solid brief." ${ }^{33}$ The central elements of storytellingsetting, conflict, character, point of view, theme, and plot-form the toolkit of the brief writer. ${ }^{84}$ And IRAC may or may not be compatible with these elements.

For example, Kenneth Chestek has noted that when a brief is not attentive to the element of character, it misses the opportunity to persuade the reader through pathos - that is, through identification with the client and sympathy for the client's position. ${ }^{85}$ But IRAC, which focuses "primarily on rule-based reasoning to the exclusion of other forms of reasoning," leaves little room for character development. ${ }^{86}$ Thus, to the extent we emphasize IRAC as a rigid organizational tool, we may inhibit the development of our students' ability to move beyond the legal rules to the "heart" of a case when they seek to communicate an analysis to a legal reader.

\section{PEDAGOGICAL DEFICIENCIES OF IRAC}

In light of all of these criticisms, why does IRAC remain the chief pedagogical tool for teaching legal writing? One scholar has suggested that IRAC "dominates the pedagogical landscape . . . because there are not many alternatives from which to choose" given legal writing's fairly recent emergence as part of the law school curriculum. ${ }^{87}$ But in today's legal education landscape, where more is known than ever before about how novice law students learn, there are compelling pedagogical reasons to revisit how and when IRAC is presented in the first year of law school.

\section{A. The Complex Subsidiary Skills Required for IRAC}

Aside from IRAC's inherent deficiencies, it is problematic for 1Ls because using IRAC effectively requires new law students to tap into a number of subsidiary skills that, for many, may still be poorly

\footnotetext{
83. Id. at 132 .

84. Id. at 137.

85. Id. at $143-44$.

86. Id.

87. Kedia, supra note 41 , at $164-65$.
} 
developed. ${ }^{88}$ In 2009, on the heels of the Carnegie Report, Nelson P. Miller and Bradley J. Charles undertook to catalogue these subsidiary skills to support their recommendation that "law schools must make plain how and what it is that students are required to learn." 89

Miller and Charles recognized IRAC as "the generally accepted way of representing legal analysis" and "assume[d] that students should use it." Nonetheless, in the next breath, they called IRAC "oversimplified" and then proceeded for the remainder of the article to identify and explain no fewer than sixteen subsidiary skills students must "master" to effectively use IRAC. ${ }^{91}$

The first category of skills, labeled preparatory skills, includes thinking and reading. ${ }^{92}$ In this context, thinking refers to the "practices that promote effective thinking," including mental energy, concentration, memory, sensory integration, organization, and "other mental states." 93 Reading includes the use of such strategies as "readiness, purpose, rereading, anchoring, evaluating, and hypothesizing" (as opposed to "only linear reading strategies like highlighting, paraphrasing, noting detail, and making margin notes"). ${ }^{94}$

How does this analytic reading strategy relate to the IRAC framework? First, students must read to know the rule - the $R$ of IRAC. Second, reading will help the student develop legal application skills - the $A$ of IRAC. And, lastly, students will gain practice with IRAC and its subsidiary skills every time they read a case because each case follows the IRAC format.

But each of these relationships between reading and IRAC is suspect. First, legal educators are keenly aware of the time and effort it takes for

88. Nelson P. Miller \& Bradley J. Charles, Meeting the Carnegie Report's Challenge to Make Legal Analysis Explicit-Subsidiary Skills to the IRAC Framework, 59 J. Legal EdUC. 192, 193 (2009).

89. Id.

90. Id.

91. Id. at 193-94. As I have discussed in previous articles, I do not view the law, or legal writing, as a "mastery subject." See Miriam E. Felsenburg \& Laura P. Graham, A Better Beginning: Why and How to Help Novice Legal Writers Build a Solid Foundation By Shifting Their Focus From Product to Process, 24 Regent U. L. ReV. 83, 90 (2012) [hereinafter Better Beginning] (encouraging law professors to deliberately teach students that "they will never learn all of the law or master it" (emphasis added)).

92. Miller \& Charles, supra note 88 , at 194-96.

93. Id. at $194-95$.

94. Id. at 196.

95. Id. (emphasis added). 
novice law students to learn to read cases and other authorities efficiently and effectively. ${ }^{96}$ Professor Ruth Ann McKinney has noted:

Take time to read with your students - carefully, closely, attentivelyand you may find many who are reading inefficiently (if dutifully) and ineffectively, identifying the wrong purpose for their reading and taking a remarkable amount of time without engaging in a meaningful way with the text. Other students, frustrated with their own inefficiency or inability to draw meaning from their reading, take shortcuts (becoming over-dependent, for example, on study aids or computer-based highlighted text) or give up on reading altogether.

Second, to say that students must be able to "read to know the rulethe $R$ of IRAC" - takes us back to Professor Sinclair's objections about the indeterminate nature of common law rules. ${ }^{98}$ Many seasoned lawyers still struggle with articulating the rule of any given case or group of cases; how much greater the struggle is for novice law students!

Third, the statement that "each case follows the IRAC format" is simply false, at least in light of the way most law professors present IRAC. 99 In fact, very few opinions follow the IRAC "formula," if that is understood to mean that they begin by stating the issue, continue by announcing the rule, and then proceed to clearly apply that rule to the facts of the case. ${ }^{100}$

Thus, while I agree that analytic reading is an essential preliminary skill to sound legal analysis, I disagree with the supposition that novice law students have the requisite analytic reading skills to smoothly transition into the world of IRAC, which they are often forced to enter on Day One of legal writing class.

The second category of subsidiary skills Miller and Charles identified is conceptual skills. ${ }^{101}$ In this category are conceptualizing, ${ }^{102}$

96. See, e.g., Ruth Ann McKinney, Teacher's Manual to ACCOMPANy ReAding LiKe A LAWYER TIME SAVING STRATEgIES FOR READING LAW LiKE AN ExPERT 5 (2d ed. 2013) (noting that as a result of changes in early public education, students "read far less today than did their peers of ten or twenty years ago"); see also Better Beginning, supra note 91, at 99-103 (recognizing that close, active reading is a key component of the pre-writing process and detailing methods that beginning law students should employ when reading and assessing legal authorities).

97. MCKINNEY, supra note 96, at 6.

98. See generally Sinclair, supra note 19.

99. Miller \& Charles, supra note 88, at 196.

100. See Benfield, supra note 17 , at 17 (noting that "very few opinions by good (or bad-but more often bad) judges use an IRAC-type system."); see also John Leubsdorf, The Structure of Judicial Opinions, 86 MINN. L. REV. 447, 451 (2001) ("The judicial opinion, despite its familiarity and the dullness of many of its exemplars, turns out to be an unexpectedly complicated and subtle genre, comparable in these respects to more traditional literary genres.").

101. Miller \& Charles, supra note 88, at 194. 
reasoning, ${ }^{103}$ generalizing, ${ }^{104}$ specifying, ${ }^{105}$ and hypothesizing. ${ }^{106}$ Again, very early in the first semester, law students certainly have not "mastered" these skills and, in fact, may not have ever been taught to consciously employ them. These are skills that most law students develop over a long time and with much practice.

The third category of subsidiary skills Miller and Charles identified is logical skills: ${ }^{107}$ deducing, ${ }^{108}$ inducing, ${ }^{109}$ and abducing. ${ }^{110}$ Miller and Charles posited that deductive reasoning is the most familiar of these three skills, because it follows the classic syllogism that starts with a major premise, followed by a minor premise, followed by a conclusion. ${ }^{111}$ Miller and Charles enthused, "This syllogism is centuries old; so it's no wonder that IRAC, which mirrors this syllogism, makes so much sense!"”112

However, as Miller and Charles then noted, deductive reasoning "may appear to be mechanical but... can involve such an array of different mental activities in different settings that it probably involves as

102. Id. at 199-202. The "ability to acquire, recall, and use" appropriate concepts is what makes lawyers "expert at legal analysis." Id. at 200. Important aspects of conceptualizing include "word recognition" (recalling and using the right words, as symbols for larger meaning), assembling schema for the structure of connected concepts, and "cognitive map[ping]" (creating "mental picture[s] or outline[s] connecting schemas to other schemas"). Id. at 200-01.

103. Id. at 202-04. Unreasoned thinking occurs when law students "think and decide primarily on the basis of [cause-and-effect] and personal preference or influence." Id. at 203. Reasoned thinking considers a statement's content rather than its cause or author, examining "different possible goals, purposes, policies, interests, and meanings." Id.

104. Id. at 204-05. Generalizing involves "synthesiz[ing] rules and holdings to state more general rules of law before applying those rules to other specific cases." $I d$. at 204 . The skill of generalizing is "one way to create the $R$ of IRAC." Id. at 205. Students also need to evaluate what is and is not a fair generalization. $I d$.

105. Id. at 205-06. "Students must develop the skill of determining whether and how to make a rule more specific to a certain situation or application." Id. at 205.

106. Id. at 206-07. Miller and Charles apparently relate this skill to the $A$ of IRAC:

When events have already occurred and the facts about them are well known, lawyers will often hypothesize other facts to fully appreciate the ... known facts. Generating hypothetical scenarios to compare and contrast other situations helps lawyers holistically judge the matter at hand. It is a form of inductive reasoning that constructs picturestories as metaphorical imagery, similar to reasoning by analogy.

Id. at 207.

107. Id. at 208 .

108. Id.

109. Id. at 209 .

110. Id. at 210 .

111. Id. at 208. For a discussion of IRAC as it relates to classical rhetoric, see supra Part II.C.

112. Id. 
much art as science." 113 They also recognized that inductive reasoning (most commonly accomplished through analogy), and not the more familiar deductive reasoning, is often the bread and butter of highly skilled trial lawyers, who often rely on storytelling to lead the court to the desired outcome. ${ }^{114}$ And as for abductive reasoning, how many longtime lawyers, much less novice law students, can define that term? ${ }^{115}$ In fact, I fear that even the word "syllogism" means nothing to a large percentage of today's 1Ls. Thus, to say that IRAC simply mirrors the classic logical syllogism does nothing to advance most students' ability to use IRAC effectively.

As if these three categories of subsidiary skills were not enough, there is yet a fourth: evaluating skills. ${ }^{116}$ These consist of evaluating, ${ }^{117}$ contrasting, ${ }^{118}$ scaling, ${ }^{119}$ satisfying, ${ }^{120}$ weighing, ${ }^{121}$ and quantifying. ${ }^{122}$

113. Id.

114. See id. at 207-08.

115. "To abduce is to infer that something may exist from the existence of other matters that are sometimes connected with the matter inferred.... Abductive reasoning is not, strictly speaking, a form of logic and can produce errors." Id. at 210. Miller and Charles did not explain how the skill of abductive reasoning relates to IRAC other than to state that it is "an evaluative aid toward finding an answer or solution," presumably by allowing lawyers to draw reasonable inferences that will lead to further fact-finding. $I d$.

116. Id. at 211-18.

117. Id. at 211-14. Students must learn to "evaluat[e] arguments to determine the logical fitness of an assertion or premise. Evaluation has to do with making sound judgments, which of course is necessary to give sound legal advice." Id. at 211. And the skill of evaluation itself has five subsidiary skills: "identifying the assertion, argument, or premise" to be evaluated, questioning it, judging what evidence is relevant, deciding whether that evidence is consistent with the premise and sufficient to establish it in the mind of a reasonable person, and identifying the implications of possible outcomes. Id. at 211-14 (emphasis added).

118. Id. at 214-15. Contrasting involves usefully comparing the hypothetical scenarios generated through the skill of hypothesizing with the facts of the case at hand ("the nuts and bolts of reasoning by analogy"). Id. at 214 .

119. Id. at 215-16. Scaling allows students to contrast hypothetical scenarios by placing them "along a spectrum or continuum from exaggerated contrasting points at either end." Id. at 215.

120. Id. at 216-17. Miller and Charles note that often it is uncertain whether an element is satisfied: "Although 'satisfying' an 'element' may sound scientific, a lawyer need not conclude with certainty. The art of being a lawyer is often in reaching appropriately qualified conclusions as to whether an element has been satisfied." Id. at 217.

121. Id. at 217-18. Weighing is the skill needed when a legal test has factors rather than elements; students must first develop a list of factors; next, align the case facts with the factors to which they relate; and finally, conclude which side each factor favors. Id. at 217. As we studied the role of pre-writing in first-year legal writing courses, Professor Felsenburg and I discovered that each of these three steps in the weighing process is immensely challenging for new law students, even in the simplest scenario. Our Pre-Writing Handbook devotes an entire chapter to identifying relevant factors, constructing a visual to represent the factors, and then inserting case facts into the visual; it then devotes another entire chapter to evaluating the strength of each factor and reaching a reasonable conclusion. See PRE-WRITING HANDBOOK, supra note 34, at 89-115. 
Of course, legal educators recognize the value of these skills and actively seek to help their students develop them. But I disagree that teaching these subsidiary skills will promote "[e]arly mastery of learning" among law students. ${ }^{123}$ Simply put, legal analysis is not a mastery subject. Certainly in the very early part of the $1 \mathrm{~L}$ year, when many legal writing professors introduce IRAC, very few students possess the subsidiary skills that Miller and Charles considered necessary to use the formula effectively.

\section{B. Novice Students' Lack of Schemata for Constructing Knowledge}

Many legal writing texts purport to teach students how to master legal writing - or, put another way, how to be "expert" legal writers. ${ }^{124}$ But I am convinced that the most that can be expected of $1 \mathrm{Ls}$ is that by the end of the year they will be "competent novices" at legal writing. ${ }^{125}$

Susan Provenzano and Leslie Kagan have summarized well the differences between expert legal writers and novice legal writers:

[E]xpert legal writers adopt specific rhetorical strategies for producing well-organized, precise, and deep legal analysis. They use reflective writing techniques and approach the writing process recursively, moving from global to local concerns and back, and from parts to wholes and back. Expert legal writers are also able to step back from their writing and imagine audience needs and responses. The expert's written product is thus reader-centered, with a clear focus on the document's communicative purpose. Novice legal writers, on the other hand, tend to view the writing process as linear, cannot remove themselves from their writing, and concentrate on telling what they know irrespective of their audience's needs. The result is a "knowledge-telling" document that memorializes the writer's thought processes but is not of great use to the reader. ${ }^{126}$

122. Miller \& Charles, supra note 88, at 218-19. Quantifying involves being able to clearly understand and communicate the level of certainty of legal conclusions, which, as Miller and Charles recognize, "involves not only judgment but experience." Id. at 219.

123. Id.

124. See, e.g., NANCy L. Schultz \& Louis J. Sirico, JR., Legal Writing ANd Other LAWYERING SKILLS 1 (5th ed. 2010) (stating that students will "master an approach that emphasizes precision, good organization, and plain English"); JOHN C. DERNBACH ET AL., A PRACTICAL GUIDE TO LEGAL WRiting \& LEgal METHOD xxv (5th ed. 2013) ("With time and practice, the finer points of legal writing and legal method can be mastered.").

125. See Michael Hunter Schwartz, Teaching Law Students to Be Self-Regulated Learners, Mich. ST. L. REV. 447, 449 (2003) (suggesting that even by the end of three years of law school, our students are, at most, "competent novice lawyers"); see also Better Beginning, supra note 91, at 92.

126. Susan E. Provenzano \& Lesley S. Kagan, Teaching in Reverse: A Positive Approach to Analytical Errors in 1L Writing, 39 LOY. U. CHI. L.J. 123, 162 (2007). 
Given these differences, IRAC as an organizational formula is an ineffective vehicle for moving students from novice even to competent novice, much less for moving them from novice to expert.

As newcomers to the "discourse community" of the law, ${ }^{127}$ L Ls have an immediate need to develop "domain-specific schemata" 128 for learning within that community. This includes substantive schemata-contexts for learning substantive doctrines and concepts - and, perhaps more relevant in the legal writing classroom, a syntactical schema. ${ }^{129} \mathrm{~A}$ syntactical schema comprises an understanding of "components of the legal system [and] the interrelationship of the various components," as well as "the conventions of the discourse and... the function and interrelationship of the basic units contained in the structure of the discourse." 130

Of course, IRAC is one such syntactical schema-it describes the units of discourse within the legal profession. ${ }^{131}$ Thus, it makes sense to introduce IRAC as a framework for legal analysis very early onperhaps on Day One of the first semester. And it might make sense to base students' first writing assignment on IRAC — but this assignment should be very narrowly tailored and simple: one clear issue, one clear rule, one straightforward factual application, and one fairly easy conclusion. ${ }^{132}$ And the evaluation of this assignment should not be related to students' written product, but to their analytical process. ${ }^{133}$

Paula Lustbader, in an important article on the cognitive learning process of law students, ${ }^{134}$ analogized this learning process to the process

127. See Nancy Soonpaa, Using Composition Theory and Scholarship to Teach Legal Writing More Effectively, 3 LEGAL WRITING 81, 87 (1997) ("Only when writers understand a new discourse community, such as the academic or professional discourse community, can they set operational goals that will allow them to meet the conventions of that new kind of writing.").

128. See Paula Lustbader, Construction Sites, Building Types, and Bridging Gaps: A Cognitive Theory of the Learning Progression of Law Students, 33 WiLLAMETTE L. REV. 315, 327 (1997) ("Without such schemata, a novice, who may understand the specifics of a substantive area, will be unable to use her knowledge effectively because she will not know the structure of the discourse, the order in which to present ideas, when to emphasize different concepts, and what information she needs to make explicit versus what information is understood implicitly.").

129. See id. at 334 .

130. Id. at 334 .

131. Id. Lustbader used the acronym (P)IRAC, including policy as a fundamental component of legal discourse. Id.

132. See Edwards, supra note 48, at 7 (noting that IRAC works well only for the simplest analysis).

133. See generally Felsenburg \& Graham, supra note 91 (suggesting strategies for facilitating students' readiness and responsiveness to learning the process of legal analysis, including setting clear and reasonable non-mastery goals, emphasizing metacognitive skills, and incorporating prewriting into the first-year legal writing classroom).

134. See generally Lustbader, supra note 128. 
of constructing a house. Lustbader posited that beginning law students begin at the preconstruction site and from there must bridge the gap to technician. "The gap between Preconstruction and Technician is the transition students make from being nonlaw students to law students."136 I believe that IRAC's function in legal writing pedagogy should be primarily to bridge this gap.

Lustbader asserted that when students have bridged the gap from Preconstruction to Technician, they have "beg[u]n to learn basic syntactical and substantive schemata" of the legal discourse community. ${ }^{137}$ Technicians can "mechanically apply basic concepts and methods to familiar problems. However, they cannot transfer their understanding to a problem that has slight variations from previous ones because they have not developed the underlying principles or schemata sufficiently."138 Thus, while technicians can "adhere strictly to the (P)IRAC structure in articulating their analysis," this adherence "often creates a form-over-substance problem."

Interestingly, the next stage in Lustbader's construction process is Drafter. ${ }^{140}$ The tasks she described in the Drafter stage sound suspiciously like the tasks we often expect our students to perform after just a few weeks of legal writing instruction. Noting that " $[t] h e$ transition from Technician to Drafter is difficult," Lustbader suggested that "[w]hereas in the Technician site it was enough for students to apply a schema by rote, as Drafters they must learn to transfer their knowledge to new situations and understand why they would apply the doctrine or policy." 141

It is at this stage that I think rigid insistence on IRAC as the organizational tool for writing is most dangerous. ${ }^{142}$ We should not be

\footnotetext{
135. Id. at 330 .

136. Id.

137. Id. at 331 .

138. Id.

139. Id. at 332 .

140. Id. at 340 .

141. Id.; see Fine, supra note 50, at 7-8 (observing that "if given the opportunity, students will react, rather than constructively create methods of analysis or challenge competing approaches. Giving students a convention within which to operate frustrates our efforts to develop in students an understanding of the process of legal analysis by deconstructing the various steps, and then structuring an analytic framework appropriate to a given task.").

142. I do think there is room for talking about IRAC throughout the legal writing course, but only as a pre-writing tool. We can thus reinforce the valuable schema that IRAC provides our students as they improve their ability to analyze legal problems without stifling their ability to move forward as legal writers- for example, from Technician to Drafter. For a detailed discussion of how IRAC can fit into the pre-writing process, see infra Parts V-VI.
} 
encouraging our students to continue to adhere to a superficial organizational structure when our goal is to help them move fairly quickly but confidently to more complex analysis and writing. ${ }^{143}$ Rather, as I argue in Part V, ${ }^{144}$ we should use IRAC as a pre-writing tool and draw on other methods of teaching written organization that better promote our students' cognitive growth as members of the legal discourse community.

\section{PRACTICAL DEFICIENCIES OF IRAC}

Perhaps the most concerning criticism of IRAC comes not from the legal academy, but from practitioners, who loudly call for better writing among new lawyers. ${ }^{145}$ Judges and senior lawyers complain that new lawyers are deficient in many areas of writing: conciseness, organization, analytical skills, precision, mechanics, and the list goes on. ${ }^{146}$ The fact that practitioners are criticizing graduates' ability to organize their legal writing ${ }^{147}$ suggests that the model of strict adherence to IRAC taught in most first-year programs is not producing good practical results. ${ }^{148}$

Even back in 1995, in the Second Draft issue devoted to IRAC, one former practitioner weighed in, expressing reservations about the "formfitted legal construct" of IRAC:

[IRAC] ... forces unprepared students to learn the hard way, at the expense of their clients, that practicing law involves understanding facts first, "what happened" and the "how" and "why" of the mess that brought the parties to the last resort of dispute resolution. Today's lawyers have to understand the problem before they ever assist others in its practical resolution. Consequently, for them to jump from issue

143. Lustbader noted that even at the Drafter stage, some novice students "may spend most of their time and mental energy reminding themselves of the conventions of the discourse." Lustbader, supra note 128 , at 343 . This suggests to me that overemphasizing IRAC for a prolonged period may drain our students of the mental energy they need to grow as legal analysts and writers.

144. See infra Part V.

145. See generally Legal Education and Professional Development-An Educational Continuum, Report of The Task Force on Law Schools and the Profession: Narrowing the Gap, 1992 A.B.A. Sec. of Legal Educ. \& Admissions to the Bar 1 (commonly known as The MacCrate Report); William M. SUllivan ET AL., EdUCATING LAWYERS: PREPARATION FOR THE PROFESSION OF LAW (2007) (commonly known as The Carnegie Report); Amy Vorenberg \& Margaret Sova McCabe, Practice Writing: Responding to the Needs of the Bench and Bar in First-Year Writing Programs, 2 PHOENIX L. REV. 1 (2009); Kedia, supra note 41, at 148-49.

146. Vorenberg \& McCabe, supra note 145, at 9-13.

147. Vorenberg \& McCabe's survey revealed that over half of the lawyers surveyed said that new law graduates' writing was disorganized. Id. at 9 .

148. According to Vorenberg \& McCabe, students reported that upon entering practice, they did "a lot of writing [but] were instructed to abandon the 'IRAC' model." Id. at 4-5. 
to rule to application and conclusion is to fabricate a problem that fits the answer predetermined for them and set forth in the court's decision.

This concern was quantified to some extent in 2009, when Amy Vorenberg and Margaret Sova McCabe surveyed a small sample of trial judges from several states to determine how current legal writing programs can better equip their students to meet the demands of practice. ${ }^{150}$ The judges who responded agreed that clear organization is a key quality of good legal writing, but they had reservations about the IRAC paradigm. ${ }^{151}$ When asked, "Do you find IRAC effective or do you prefer organization that combines rule explanation with application to client facts?" several judges stated a preference for the latter. ${ }^{152}$ They noted that "the use of an organizational paradigm that separates 'explanation' from 'application' is not helpful where a particular legal issue is settled and frequently before the court." ${ }^{\text {"153 }}$ And the judges noted that even when an issue is not settled, the "complexity and nature of the issue" should dictate the structure and depth of analysis, not a set paradigm. ${ }^{154}$

Vorenberg and McCabe reported that "[m]ost of all, judges expressed a desire for writers to understand their task and vary their approach depending on the legal issue at hand."155 They concluded that legal writing students need "greater training in tailoring their analytic approach to the legal issue."156 As part of this training, "law-school writing classes should be less rigid about using IRAC or similar organizational paradigms." 157

\footnotetext{
149. Manning Warren, IRAC Response, ThE SECOND DRAFT (Legal Writing Inst., Tacoma, Wash.), Nov. 1995, at 19.

150. Vorenberg \& McCabe, supra note 145, at 3-4.

151. Id. at 17 .

152. Id.

153. $I d$.

154. Id. at 7. Vorenberg and McCabe provided the judges with three briefs written by first-year law students. Two of the briefs were organized using the IRAC paradigm ("explaining the law first and then applying the law to the facts") and the other brief "allowed for greater organizational flexibility and often combined explanation of the law with application of client facts in the same paragraph." Id. at 14 . Overall, the judges ranked the brief that took the "integrated approach" higher than the briefs that followed IRAC. Id. at 14-16.

155. Id. at $17-18$

156. Id. at 23 .

157. Id. "It is important that students do not learn that following IRAC or similar models automatically produces high-quality legal writing." $I d$. at 26 . Vorenberg and McCabe advocate "allow[ing] students more opportunities to practice" varied writing skills "depending on audience and subject matter" and "facilitat[ing] more discussion about what analytical content the legal reader needs and the best way to provide it." Id. at 23, 27; see also Rebekah Hanley, Becoming-or
} 
[A]n inductive, problem-solving based method... recognizes the nuances of actual legal problems presented by actual clients-issues that are not easily resolved by finding the "correct" rule, but are more heavily dependent on an appropriate analysis of the facts, an application of the law to the facts, and a shaping of the resulting analysis toward achieving the client's goals.... [T] his approach makes some aspects of legal reasoning and argument easier for students to absorb ... [and] eliminat[es] the simplistic nature of the step-by-step IRAC approach, thus helping students to become legal analysts and problem solvers rather than mere legal technicians. ${ }^{158}$

In sum, as Provenzano and Kagan observed, in law practice there is a "spectrum of acceptability" within which a writer's work can fall. ${ }^{159}$ While using IRAC might, in many situations, result in a memo or brief that is somewhere on that spectrum, it will not always result in the best or most acceptable product. ${ }^{160}$ We need to teach our students a better way to create a written product that will meet the needs and expectations of their readers - in terms of content, structure, style, and mechanics ${ }^{161}$ once they enter the practice of law.

\section{A NEW APPROACH tO THE UTILITY OF IRAC}

The previous sections of this Article have laid out the various shortcomings of IRAC as a tool for teaching legal writing. They have also emphasized the tension created by using a formula that at its best can convey only the simplest legal analysis, and thus must be presented very early in the first semester - the very time that we want our novice students to be building meaning for themselves.

I believe that over the many years IRAC has been used in legal writing classes, legal writing professors have turned what was meant primarily as an analytic tool into a writing formula, to our students' detriment. In this part of the Article, I propose a return to IRAC as I

Hiring-A Capable Legal Writer: The Formula, 71 OR. BULL. 11, 11-12 (2011) ("expert legal writers do not strictly follow the organizational paradigms commonly taught to beginning legal writing students").

158. Kedia, supra note 41 , at $171-72$.

159. Provenzano \& Kagan, supra note 126, at 131.

160. See Kedia, supra note 41 , at 150 (forcefully asserting that "[i]n essence, IRAC is nothing more than an imprecise organizational tool").

161. See George Gopen, IRAC, REA, Where We Are Now, and Where We Should Be Going in the Teaching of Legal Writing, Keynote Address at the Capital Area Legal Writing Conference (Feb. 26, 2011), available at $\mathrm{http}: / / \mathrm{www} . j o u r n a l l e g a l w r i t i n g i n s t i t u t e . o r g / a r c h i v e s / 2011 / 17$ LegalWritingxviixxxv.pdf (arguing that rigid adherence to IRAC as a pedagogical approach prevents legal writing professors from teaching students how to persuasively construct sentences and paragraphs, which is the art of legal writing). 
believe it was meant to function, and I offer some alternative, IRAC-free strategies for teaching our students how to organize their writing.

\section{A. Returning IRAC to Its Proper Place As a Starting Point for Pre- Writing}

While no one seems to know the precise origin of the IRAC acronym, ${ }^{162}$ it likely did not originate as an organizational paradigm for legal writing. More likely, it originated as a simple mnemonic for the basic steps of legal analysis: Begin with the question posed (Issue), identify the legal rules that govern that issue (Rule), apply those rules to the facts at hand (Application), and then decide what result most likely follows (Conclusion). ${ }^{163}$ Viewing IRAC in this way, no reasonable person would quarrel with its validity. But this basic mnemonic for the steps of legal analysis will not get law students past the first week of law school; they need in-depth instruction on how to do legal analysis. ${ }^{164}$

My own approach to teaching students how to analyze legal problems has changed significantly in the past several years; I have become increasingly deliberate about incorporating pre-writing into my first-semester legal writing course. By pre-writing, I refer to the process that students should use to analyze a given legal writing assignment before they ever begin outlining a written document. I spend the entire first month of the Fall semester exclusively on pre-writing, and I return to it throughout the year. During the first month, I do not assign any

162. See Kedia, supra note 41, at 152 ("Though many scholars reference IRAC in legal writing literature, there is no clear record of its genesis and underlying principles."). Richard Neumann is reported to have said that IRAC is "useful for exam-taking, but ineffective for memoranda and briefs." Nancy Soonpaa, The Continued Vitality of IRAC, THE SECOND DRAFT (Legal Writing Inst., Tacoma, Wash.), Nov. 1995, at 15 (citing Richard K. NEUMANN, JR., LEgal REAsoning AND LEGAL WRITING 231 (2d ed. 1994)). This suggests that perhaps IRAC originated outside the legal writing context. Kedia's article supports this theory: "IRAC works well for exams, where fact patterns are provided, a set of defined legal issues are learned ahead of time, and a set of defined legal rules have been extracted from cases throughout the semester." Kedia, supra note 41, at 171.

163. See, e.g., Jo Anne Durako, Evolution of IRAC: A Useful First Step, The SECOND DRAFT (Legal Writing Inst., Tacoma, Wash.), Nov. 1995, at 6 ("I use IRAC during my second class meeting as an early introduction to one possible structure for analyzing a simple legal problem." (emphasis added)).

164. Kedia, supra note 41 , at 149 ("There are very few, if any, times in a lawyer's education when someone takes the time to deliberately and systematically teach the student what legal analysis is, how to do it, and, most importantly, why it is necessary to help resolve a client's problem."). Kedia noted that "IRAC does not explicitly teach students to formulate legal analysis" and recommends that "professors should ensure that students understand the ways the law can be interpreted and applied before requiring them to physically write an analysis or even a simple rule explanation which could be based on a faulty or incomplete understanding of the legal sources they are using." Id. at $150-51,172$. 
formal legal writing, so that students can practice and gain confidence in their analytical skills. I rarely use the term "IRAC" when teaching prewriting strategies, although the teaching techniques I use do cover the four components of IRAC.

For example, I give my students pre-writing worksheets for their first several assignments. Here is the worksheet I use for a simplified burglary analysis:

1. Read the e-mail to you from Regina Nance. ${ }^{165}$

2. Make a bulleted list of the aspects of Mr. Jones's ${ }^{166}$ story that seem important.

3. Identify and write below the broad question Ms. Nance needs you to answer.

4. Identify and write below any specific parameters of your assignment that will help you focus your work as you proceed.

5. Read the North Carolina common-law burglary definition and the burglary statute that Ms. Nance has provided to you. Highlight or circle the key elements.

6. Of the elements you identified in your answer to Question 5, write below the ones that appear to be "givens" in Mr. Jones's story and the facts that suggest that they are "givens."

7. Given the facts of Mr. Jones's story as you now know them, and the elements of burglary you've identified, preliminarily identify the narrow issue you must analyze in order to answer the general question you identified in Question 3. Write the preliminary narrow issue below.

8. Read the Fields case once without taking any notes. Write below any thoughts that occur to you about how the case might help address the preliminary narrow issue you identified in Question 7.

9. Now read the case again, closely and actively, taking notes in a format that is useful to you. Note any new information you learn from the case that will assist you in analyzing the preliminary narrow issue you identified in Question 7.

10. If your reading of the case has led you to a new understanding of the narrow issue you must analyze, write the revised narrow issue below.

165. The hypothetical public defender in the jurisdiction in which the problem is set.

166. The hypothetical defendant who has been charged with first-degree burglary. 
11. Identify the relevant categories of fact that seemed important to the result in the Fields case. Create a visual representation of those categories, and include in your visual the key facts of the authorities and of Mr. Jones's story, as they relate to those categories.

12. Based on your visual representation, analyze Mr. Jones's scenario and decide how the narrow issue you identified in Question 7 (or Question 10) would likely be resolved. Be sure you consider all reasonable, possible outcomes. Write below your decision and the key reasons for it.

As the students work through these questions, they are thinking about each element of IRAC, but in a recursive way rather than in the linear way suggested by IRAC. And the questions use the same terminology that I use in class-terminology that recognizes the complexity of legal analysis but helps demystify it.

For example, questions 1-3 are designed to help students identify the broad question the scenario raises, and question 6 is an intermediate step that helps students focus their thinking; but it is not until question 7 that students are asked to articulate the narrow (deep) issue (the analog to the $I$ of IRAC). And question 10 recognizes that it may be necessary to revisit the initial formulation of the narrow issue after further reading and analysis. These questions, viewed together, reinforce the basic truth that often, a lawyer must do considerable work just to arrive at the narrow legal question that his or her analysis must address.

Likewise, questions 5 and 9 both relate to the rules (the $R$ of IRAC) that govern the analysis. Question 5 leads students to the general rules that govern the analysis, and then question 9 builds on that by requiring students to articulate the sub-rules from the authorities that help them understand and apply the general rules to the fact pattern. And question 11 requires students to organize (and perhaps even synthesize) the subrules into a logical framework within which to place the facts of the problem. This approach to the rules allows students to be "knowledge builders" rather than just "knowledge-tellers."

Questions 11 and 12 relate to the application and conclusion portions of the analysis (the $A$ and the $C$ of IRAC). Question 11 reminds students that their analysis of how the rules apply to the facts must be grounded in the sub-rules they have identified. And question 12 encourages students to remember the concept of counter-analysis. Question 12 also helps students become comfortable with the ambiguity of the law by asking them to decide the likely outcome. Finally, question 12 illustrates that 
the conclusion of any legal analysis should be driven primarily by reason, not by emotion or intuition.

After working through these questions, I quickly point out that what we have just done is consistent with the basic IRAC model for legal analysis that we discussed on Day One. I think this point is an optional one; I make it just to allow my students to hear the term "IRAC" once again, so that if another law professor or a future employer refers to it, the students will understand the meaning of the term.

\section{B. Teaching Legal Writing Structure Without IRAC}

I recognize that the premise of this Article - that IRAC is helpful as a basic analytical tool but not as a paradigm for organizing legal writing - begs the question of what alternatives are available to teach students about organizing legal writing effectively. I agree with Pollman and Stinson that "writing law ... require[s] unambiguous precision" and that any terminology we might substitute for IRAC must serve that requirement. ${ }^{167}$ The key is "giving [our] students the tools needed to talk about writing in a sophisticated and meaningful way." 168 I think this can be done without the necessity of agreeing upon any one paradigm, using a variety of plain-language terms that will resonate and "stick" with our students.

The following passage from a 2007 article on giving effective feedback on student writing provides a good example of this kind of plain-language term:

One common target form in legal writing is the objective analytical memorandum that applies law to client facts to determine a likely answer to a legal question. Legal memoranda have core legal reasoning components that appear in predictable "intellectual locations." In these intellectual locations, law-trained readers find rules of law, explanations of precedent, and applications of law to fact. ${ }^{16}$

The concept of "intellectual location" would seem to be a natural starting point for teaching novices how to structure a memo.

167. Pollman \& Stinson, supra note 60 , at 244 .

168. Id. at 245 .

169. Provenzano \& Kagan, supra note 126, at 144 (emphasis added) (citing Mary Beth Beazley, The Self-Graded Draft: Teaching Students to Revise Using Guided Self-Critique, 3 LEGAL WRITING 175, 177 (1997) (coining the term "intellectual locations")). 
First, it has the advantage of being reader-based. Legal readers expect a lawyer's analysis to incorporate "agreed-upon analytical elements":

[W] hen making a legal argument, it is expected that 1) the writer will articulate a rule for the court to apply, 2) the writer will cite to the best possible authority for that rule, 3) the writer will explain any ambiguities in the rule, usually by illustrating how the rule has been applied in the past, and 4) the writer will explain how the rule should be applied in the pending action. ${ }^{170}$

The legal writing professor can then illustrate that in most situations, putting the elements in this order meets the intellectual expectations of the reader. This can be done easily without continually mentioning the IRAC "formula."

A second advantage of the concept of "intellectual location" is that it allows students to begin to construct their own schemata for communicating legal analysis by allowing them to think for themselves about the best "intellectual location" for any given analytical component.

For the same reasons that "intellectual location" would work, "intellectual weight" would work as a companion term, to help students understand that the level of detail they need to include about the analytical elements will vary from memo to memo, depending on the type of analysis required. Where an analysis requires students to analogize and distinguish precedential cases to their own case facts, the reader expects the explanation of the rule to be relatively "heavy." In contrast, where an analysis requires students to use rule-based reasoning instead of analogical reasoning, the reader might expect the explanation of the rule (the description of the precedential case's key facts, holding, and reasoning) to be quite "light." And where an analysis requires students to discuss policy, the explanation of the rule might be "heavier" with regard to the holding and reasoning but "lighter" as to the key facts of the case that articulates the rule.

Professors can effectively use sample memoranda to illustrate the concepts of "intellectual location" and "intellectual weight." Instead of using the samples to point out IRAC structure (here is the I, here is the R, here is the explanation of the R, here is the A, here is the C), they can discuss with their students why the writers placed certain information in certain "intellectual locations" and what "intellectual weight" the writers placed on that information and why.

170. Beazley, supra note 169 , at 178 . 
These two terms can be used in conjunction with any number of other terms that legal writing professors have coined to teach structure. For example, the term "deep issue" 171 can be used to describe the narrow legal question the memo answers, as distinguished from the broad question the hypothetical "senior partner" may have posed. The term "roadmap" or "landscape" can be used to describe the introductory portion of the analysis in which the writer leads the reader from that broad question to the "deep issue."172 The term "broad governing rule" can be used to describe a statute or a common law test that governs the broad question, and the term "sub-rules" can be used to describe the narrower rules that illustrate how the broad governing rule operates. Our legal writing texts are replete with good terminology that we can use consistently to describe the various components of a written analysis. ${ }^{173}$

This approach is fully consistent with the conclusion reached by Tracy Turner in her 2012 examination of the current role of IRAC in legal writing. ${ }^{174}$ In her article, Turner hoped to "liberate the core principles of effective organization from acronyms so that lawyers can talk to one another about organization without debating the merits of a particular method they learned in law school or from their first mentors in the profession." "175 To that end, Turner reviewed the then-current editions of every available textbook on legal writing published or republished in the ten prior years and a large number of articles addressing IRAC and other related acronyms, seeking to answer five questions: ${ }^{176}$

1. If the text uses an acronym (e.g., IRAC, CRAC, CREAC, etc.), what is it and how does the author describe each component? If not, summarize the lessons the text offers regarding organization.

2. How does the author justify the acronym or organization the book discusses?

171. BRYAN GARNER, THE WINNING BRIEF 49 (1996).

172. If a pre-writing worksheet such as the one reproduced above is used for an assignment, we can conveniently note that all of the information generated when answering questions 1-7 belongs in the landscape or roadmap paragraphs.

173. But see Terrill Pollman, Building a Tower of Babel or Building a Discipline? Talking About Legal Writing, 85 MARQ. L. REV. 887, 889 (2002) (noting that legal writing professors "have not yet established a uniform common vocabulary within the legal writing academy").

174. Turner, supra note 66, at 356-60.

175. Id. at 354 .

176. Id. (Turner reviewed all the books "available in [her] school's law library or on [her] bookshelves"). 
3. Does the author address single v. multiple IRACS? Summarize the lessons offered.

4. Does the text discuss topic sentences? Summarize the lessons offered....

5. Does the text discuss a need to complete discussion of the law before applying the law to the facts? ${ }^{17}$

Turner concluded that among legal writing professionals there is "broad consensus" on four core principles of effective organization in legal documents, the first of which is rule-centered analysis. ${ }^{178}$ She noted that "the quest to capture some of the complexity of legal analysis has led to an explosion of alternative acronyms" ${ }^{179}$ which may have had the undesired effect of "obscur[ing] the main point of IRAC: legal analysis must begin with the law as its starting point."180 She also noted that students must grapple with the pieces of the broad rule and how the sub-rules relate to the broad rule in order to determine both the "intellectual location" and the "intellectual weight" of the various pieces of the analysis - in other words, to organize the analysis effectively for the reader. ${ }^{181}$

Teaching students (1) to use IRAC as a basic pre-writing tool and (2) to organize their written analysis using a rule-based approach (describing that approach using the terms suggested above) would alleviate many of the concerns about the use of IRAC described in Parts II-IV of this Article.

First, it would allow students the freedom to wrestle with the various components of legal analysis in a more meaningful way. Take the $I$, for example. Of course, every legal analysis begins with an Issue-a question that the analyst must answer. That is as far as we need to go with the $I$ of IRAC. Then, as a pre-writing matter, we should teach our students to recognize that in all but the simplest legal analysis, there is at least one broad issue (is your client likely to be convicted of first-degree

\footnotetext{
177. Id. at 354-55.

178. Id. at 355 .

179. Id. at 357. See generally supra Part II.C. (reviewing many of these acronyms).

180. Turner, supra note 66, at 357.

181. In her 2010 article, Soma Kedia advocates an even softer approach to thinking about and communicating legal analysis, which she calls "outcome-oriented" rather than "rule-oriented." Kedia, supra note 41 , at 151. "Rather than understanding legal writing as technical, rule-oriented analysis, I aim to think of legal writing simply as writing in the context of a system bound by rules of law-as outcome-oriented rather than rule-oriented - while still focusing on teaching students the distinguishing features of writing as a lawyer." Id.
} 
burglary?) and one or more narrow (deep) issues (was the structure he broke into a dwelling?).

Even when students are ready to begin drafting the written analysis, there is no need to revert to mentioning IRAC. We can say, "In terms of intellectual location, your discussion needs to start with the broad question first, and then you need to lead your reader to the deep issue by way of a solid roadmap paragraph."

A similar approach to the $R$ works well. At the pre-writing stage, we should teach our students simply that to answer the deep issue-and sometimes to identify it - they must find (or construct) and understand the applicable rules from the relevant authorities. There are broad rules (the elements of first-degree burglary, for example) and more specific sub-rules that clarify, expand on, limit, or state exceptions to the broad rules (the sub-rules regarding what constitutes a dwelling, for example). ${ }^{182}$ And both the broad rules and the sub-rules may be explicit, or they may have to be synthesized.

When the students are ready to begin writing about the rule, we can still instruct them without reference to IRAC. We might say, for example, that the level of detail in the case illustrations will vary according to the "intellectual weight" of the rule the case illustrates:

The broad rule in your roadmap stating the elements of burglary isn't very intellectually weighty, so the case you're citing for that rule doesn't need heavy explanation. There's no need to go into the key facts, holding, and reasoning of that case. But the sub-rule about what makes a structure a dwelling carries a lot of intellectual weight. It gives you the factors that form the basis of your analysis, and it shows how those factors have been applied in previous cases. So the cases you're citing there need more explanation; you need to spend considerably more time on their key facts, holdings, and reasoning.

Moving to the $A$, we should emphasize at the pre-writing stage that the application part of the analytical process is rarely a simple matter of matching up facts in a mechanical way; effective application requires careful reasoning (often by analogy but sometimes also using policy) and

182. See Blumenfeld, supra note 12, at 3 (recognizing the need to instruct students that a rule segment "consists of two pieces: a general rule usually derived from a statute or caselaw, and cases that explain that rule and illustrate how it has been applied to specific fact situations in the past"). Blumenfeld's suggested acronym replaces the R of IRAC with G (general rule) and P (precedent). Id. My point in this Article is that there is no need to create some new acronym reflecting the relationship between broad rules and sub-rules; we can simply say, "First, articulate the broad rule, then explain it by discussing the sub-rules from the cases, giving the explanation whatever intellectual weight it merits." 
careful consideration of possible analyses and counter-analyses. We need to give our students helpful, concrete strategies for moving through the application stage of the analysis, and we need to help them become comfortable with the uncertainty of the outcome. ${ }^{183}$

When students move to writing about the application, we still need not revert to discussing IRAC. We can simply teach them how to construct the application logically, using the terms suggested above or other helpful terms:

Here, you want to arrange your application so that you first tell your reader the factual similarities and distinctions that drive the result you think is most likely, being sure to explain their legal significance. Then, you want to alert the reader to any reasonable counter-analysis, giving it as much intellectual weight as it merits. If there are policy considerations, you need to think about the best intellectual location for those. ${ }^{184}$

And, to recognize the role of storytelling, we might add, "And in the end, you need to consider how well your application weaves in the elements of story that will resonate so deeply with your reader."

Second, this approach to IRAC (using it as a basic description of legal analysis instead of a formula for organizing legal writing) would eliminate the need to come up with different and ever-more-complex variations on the IRAC acronym to account for the structural complexities of legal analysis. On any given assignment, students would be able to construct their own "best" organization, within the parameters of applicable rules, using the "intellectual location" concept.

In all of the above examples relating to the writing portion of a firstdegree burglary problem, the hypothetical professor is touching on each element of IRAC and is emphasizing principles of effective organization. But the language used makes it more likely that students will practice independent thinking as they outline and draft the discussion. Students will be constructing their own schemata for assessing how to best arrange the pieces of each analysis, rather than trying to fit the pieces of every analysis into one rigid IRAC (or CRuPAC or IGPAC or RAFADC) mold. Their writing will be less "knowledge-telling" and more "knowledge-creating."

183. See Graham \& FelsenBURG, supra note 34 , at 111-13.

184. This would help eliminate the rote application sections we often see (especially among novice legal writers) - "Like fact A, fact A1. And like fact B, fact B1. But unlike fact C, fact C1. Because there are more likes than unlikes, the result here is the same as the result in the precedential case." 
Finally, this approach to IRAC would give legal writing professors the flexibility to use more varied assignments throughout the year. For example, with adequate time for pre-writing, we could assign firstsemester law students a memo that allows them to explore how policy arguments fit in to an objective analysis (instead of waiting until the second semester, or even the second year, to introduce policy arguments). We could more easily replace the traditional office memo discussion, which is perhaps more IRAC-compatible, with a client letter, or an email assignment, or other kinds of legal communications that do not rely on a rigid IRAC structure. ${ }^{185}$ In this way, we would be addressing some of the concerns expressed by practitioners about new lawyers' rote reliance on IRAC.

\section{CONCLUSION}

The firm entrenchment of IRAC in legal writing pedagogy suggests that it would be difficult, if not impossible, to completely replace it with another paradigm or teaching method. And I do not advocate that IRAC should be forever banished from the legal writing classroom. My Article is intended to advance the conversation about IRAC's utility as a tool for teaching the how-tos of legal writing and to suggest some strategies for those professors who wish to "pull back" from rigid reliance on it. By drawing on IRAC's strength as a basic analytical framework for legal analysis and teaching students helpful pre-writing strategies they can deliberately employ when conducting legal analysis, we can move them more comfortably into the writing stage, giving them maximum flexibility to create products that work for their legal readers.

185. See generally Katie Rose Guest Pryal, The Genre Discovery Approach: Preparing Law Students to Write Any Legal Document, 59 WAYNE L. REV. 351 (2013) (arguing that first-year legal writing courses should teach students how to approach new "genres" of legal writing beyond traditional office memos and other standard documents). I believe that focusing less on IRAC as a writing tool will make it easier for our students to transfer skills from one legal document genre to another. 